\title{
SER PROFESSOR: VOCAÇÃO OU FALTA DE OPÇÃO? OS motivos que envolvem a escassez de jovens na profissão docente no Brasil
}

\author{
Sidnei Ferreira de Araújo \\ Marcelo Máximo Purificação
}

Universidade Estadual do Mato Grosso Sul - UEMS

Centro Universitário de Mineiros - UNIFIMES

\begin{abstract}
Resumo: Apesar dos altos investimentos, o sistema educacional brasileiro tem se mostrado ineficaz devido aos maus resultados obtidos pelos alunos em exames institucionais. Esse nível de aprendizagem aquém do esperado costuma ser atribuído à falta de atualização profissional dos professores diante das novas demandas tecnológicas e pedagógicas, além da falta de ímpeto dos governos em buscar soluções para a desvalorização dos profissionais da educação. Este estudo tem como objetivo investigar as causas da aversão à possibilidade de ingresso na carreira docente adquirida por jovens do ensino fundamental e médio ao longo de sua permanência na educação básica. Por meio de revisões bibliográficas e censos, a pesquisa corrobora a tese do envelhecimento progressivo dos professores de 2009 a 2018 e o baixo interesse dos jovens pelo ensino. O estudo também revela o cenário de perda de empregos motivada por baixos salários e condições de trabalho. Para aumentar a atratividade da carreira docente, não basta investir apenas em reformas estruturais e na oferta de empregos, é preciso mudar o rumo dos objetivos das políticas públicas de educação. É necessário investimento na melhoria dos salários e plano de carreira docente para que os alunos sintam interesse na profissão. Por mais que esteja em uma escola estruturada e com todos os materiais necessários, o professor não fará um trabalho satisfatório se não se sentir valorizado e acolhido no ambiente escolar.
\end{abstract}

Palavras-chave: Carreira docente; Jovem; Desvalorização profissional

\section{BEING A TEACHER: VOCATION OR LACK OF OPTION? The reasons for the scarcity of young people in the teaching profession in Brazil}

\begin{abstract}
Despite the high investments, the Brazilian educational system has been shown to be ineffective due to the poor results obtained by students in institutional exams. This level of learning below expectations is usually attributed to the lack of professional updating of teachers in the face of new technological and pedagogical demands, in addition to the lack of impetus from governments to seek solutions for the devaluation of education professionals. This study aims to investigate the causes of aversion to the possibility of entering the teaching career acquired by young people in elementary and high school throughout their stay in basic education. Through bibliographic reviews and censuses, the research corroborates the thesis of the progressive aging of teachers from 2009 to 2018 and the low interest of young people in teaching. The study also reveals the scenario of job losses motivated by low wages and working conditions. To increase the attractiveness of the teaching career, it is not enough to invest only in structural reforms and in the offer of jobs, it is necessary to change the direction of the objectives of public education policies. Investment in improving salaries and a teaching career plan is necessary for students to feel an interest in the profession. As much as he is in a structured school and with all the necessary materials, the teacher will not do a satisfactory job if he does not feel valued and welcomed into the school environment
\end{abstract}

Key words: Teaching carrer; Young; Professional devaluation

Como citar o artigo: ARAÚJO, Sidnei Ferreira. PURIFICAÇÃO, Marcelo Máximo. SER PROFESSOR: VOCAÇÃO OU FALTA DE OPÇÃO? Os motivos que envolvem a escassez de jovens na profissão docente no Brasil. Revista Científica Novas ConfiguraçõesDiálogos Plurais, v. 2 n. 1, 2021

\section{INTRODUÇÃO}

Apesar da boa intenção das políticas de incentivo ao aumento de vagas nas universidades, é crescente o número de cursos de licenciatura fechados por falta de candidatos no Brasil. Em 2018, uma pesquisa realizada pela OCDE (Organização para a Cooperação e Desenvolvimento Econômico) revelou que "dos jovens de 15 anos que estão cursando o ensino médio, apenas $2 \%$ (dois por cento) têm a pretensão de ingressar na carreira docente. " (JORNAL ESTADÃO, 2018).

Para entender esse fenômeno, é necessário esmiuçar a imagem social distorcida do professor criada pela visão mercantilista de classes dominantes. Nesta visão, ele é importante na formação dos jovens para que eles sejam inseridos no mercado de trabalho, sem capacidade de refletir e intervir nas demandas sociais. Além disso, não há autonomia no 
desenvolvimento do trabalho pedagógico, nem valorização digna. Paulo Freire critica o status social que é atribuído aos professores, afirmando que

\begin{abstract}
Ninguém nega o valor da educação e que um bom professor é imprescindível. Mas, ainda que desejem bons professores para seus filhos, poucos pais desejam que seus filhos sejam professores. Isso nos mostra o reconhecimento que o trabalho de educaré duro, difícil e necessário, mas que permitimos que esses profissionais continuem sendo desvalorizados. Apesar de mal remunerados, com baixo prestígio social e responsabilizados pelo fracasso da educação, grande parte resiste e continua apaixonada pelo seu trabalho. (FREIRE, s/d).
\end{abstract}

Aqueles que continuam apaixonados pela profissão, permanecem por falta de oportunidade em outros mercados, ou pela vocação, que é uma justificativa muito utilizada pelos responsáveis pelas leis educacionais para explicar a falta de reconhecimento. Procura-se associar o trabalho do professor a uma atividade celestial, que deve ser realizada por amor, sem pensar em compensação social ou financeira. Como se o professor fosse um beato obrigado a ter voto de pobreza e "castidade social".

A desvalorização profissional, o desprestígio social e as péssimas condições de trabalho são as mais recorrentes tentativas de explicação para sanar os questionamentos apontados em relação à cada vez mais escassa presença de professores jovens nas escolas de ensino primário e médio. Porém o problema é mais complexo, e não dá para ser aclarado em apenas três respostas. Gentili (2008, p. 47) afirma que:

o quadro se torna ainda mais dramático quando observamos a ofensiva ideológica conservadora lançada
contra os professores nos últimos anos. Eles são responsabilizados pela profunda crise dos sistemas
escolares e lhes é atribuída a culpa pelas péssimas condições de aprendizagem dos alunos e alunas, pelas
altas taxas de repetência, pelas escassas oportunidades de inserção no trabalho para os recém-saídos
do sistema escolar, pela violência dentro e fora das escolas e pela falta de participação cidadã nas
questões mais relevantes que nossas sociedades devem enfrentar.

É necessário buscar respostas desde as raízes da formação docente no Brasil até chegar à crescente degradação dos dias atuais. Por que a escola está tão distante da realidade social e cultural dos jovens? Como melhorar o déficit qualitativo da educação no Brasil, sendo que as pessoas não querem entrar na profissão docente? Por que o professor sofre tantas pressões e violências no espectro psicológico e social, sem que haja um engajamento político e da comunidade para alterar essa conjuntura?

A presente pesquisa tem o propósito de investigar a fuga dos jovens brasileiros do magistério, buscando dados da formação docente através de revisão bibliográfica de obras históricas, além de dados de pesquisas recentes sobre o interesse de jovens do ensino médio na carreira docente.

Além dos objetivos supracitados, o trabalho visa entender a mercantilização do trabalho docente e suas consequências para a formação do aluno, visto que a dicotomia entre educação para o trabalho e aluno crítico-reflexivo é uma lacuna que os currículos escolares ainda não conseguiram preencher.

Como resultado, almeja-se reunir respostas que possam contribuir para minimizar a falta de atrativos que a carreira docente oferece aos futuros profissionais, sugerindo mudanças na estrutura de formação docente desde a sua raiz organizacional, passando pelas leis educacionais, até fatores de formação e valorização do professor. 


\section{2 - PROFISSÃO E VOCAÇÃO}

No Brasil, o princípio do magistério foi marcado pela predominância do ensino jesuítico, que era feito por padres da igreja católica. Após esse período, a tendência à educação laica se espalhou com uma forte predisposição ao ensino científico e técnico. Essa mudança deu ao professor a condição de detentor de conhecimentos considerados de suma importância para o aluno entrar no mercado de trabalho.

Em contrapartida, apesar do status social relevante para a sociedade, a desvalorização financeira continuava. Por essa razão, os homens eram seduzidos pelo discurso da iminente expansão da indústria e do comércio já disseminada no continente europeu, migrando, assim, para profissões com menos notoriedade, mas que ofereciam maior compensação pecuniária.

Além disso, os professores não tinham autonomia para desenvolver e aplicar seu método de trabalho pedagógico, sofrendo forte influência externa nas atividades docentes, tanto por parte da igreja quanto pelo governo. Essa intervenção tinha o claro propósito de disseminação dos valores ligados aos que estavam no poder, e o professor servia como instrumento de reprodução dessas doutrinas.

Para explicar o movimento de doutrinação utilizado na escola pelos detentores do poder, Bourdieu (1989) cria o conceito de violência simbólica, afirmando que

É enquanto instrumentos estruturados e estruturantes de comunicação e de conhecimento que os sistemas simbólicos cumprem a sua função política de instrumentos de imposição ou de legitimação da dominação, que contribuem para assegurar a dominação de uma classe sobre outra (violência simbólica) dando o reforço da sua própria força às relações de força que as fundamentam e contribuindoassim, segundo a expressão de Weber, para a 'domesticação dos dominados' (BOURDIEU, 1989: p.11).

A violência simbólica citada por Bourdieu não é aquela que dói no corpo físico. É o sentimento de culpa por não se adequar a algo imposto pela sociedade, como a sexualidade, o padrão de beleza, os conceitos de certo e errado que foram feitos pelos governantes e detentores do poder, que querem perpetuar essa hegemonia.

A realidade tem um começo de mudança com a implantação e disseminação de planos de expansão educacional. Nesta nova perspectiva, a escola passa a ser um direito de todos os cidadãos e não um luxo oferecido apenas aos mais ricos. O problema é que o estado não adequou a destinação de recursos às novas demandas educacionais, gerando uma defasagem estrutural que não supria tal demanda.

Com isso, a importância e o salário do professor diminuem, pois, o mestre já não era mais tutor da formação dos futuros líderes da sociedade. Seu papel mudava para uma visão mais inclusiva e igualitária, fato que não foi bem aceito pelas classes dominantes.

A desvalorização financeira, somada aos métodos engessados de organização curricular, geraram um movimento de debandada masculina das salas de aula, abrindo espaço para a entrada das mulheres.

O ingresso da mulher na docência surge como uma das explicações para a desvalorização da profissão, pois em meados do século XIX, a presença feminina no mercado de trabalho ainda era um tabu a ser quebrado. As oportunidades de ingresso eram mínimas, e a lacuna deixada pelos homens no magistério tornou-se o grande ensejo para a emancipação da figura feminina apenas como cuidadora do lar. Sforini esclarece a irrefutável visão masculina e paternalista da época em relação à mulher no trabalho docente, afirmando que

Chegamos, enfim, ao suporte ideológico da feminização docente: na representação dos homens da época, a mulher é naturalmente portadora das qualidades que se desejareproduzir em cada cidadão-trabalhador, o que foi fundamental para a sua projeção noséculo XIX, enquanto mãe e professora. $\mathrm{O}$ argumento discursivo que a legitima comoprofessora não é, portanto, o elemento intelectual, mas seus "instintos" maternais, quesão sinônimos de fé, sensibilidade, devotamento, abnegação; enfim a maternidade é coração e sentimento. A imagem sacralizada da mãe transpõe-se para a professora. Nos discursos da época repete-se exaustivamente esta relação, enquanto na prática, omagistério vai, gradativamente, adquirindo feições femininas (SFORNI, 1997, p. 752).

Com todas as qualidades citadas acima, procurava-se atribuir à mulher um status de detentora de capacidades intrínsecas da profissão docente. Essas características, por serem inatas, eram consideradas como extensão das atividades domésticas, numa clara tentativa de descaracterização da formação acadêmica das profissionais do magistério, e, por conseguinte, oferecer salários e condições de trabalho inferiores à época em que os homens predominavam na carreira; condições estas que já estavam defasadas. 
Em 2017, O INEP (Instituto Nacional de Estudos e Pesquisas Educacionais Anísio Teixeira) divulgou um estudo sobre o perfil dos professores no Brasil, revelando que "os professores típicos brasileiros em 2017 são mulheres (81\%). " Esse número deixa claro a predominância da mulher no magistério, porém, quando se trata dos setores mais valorizados da profissão, como a universidade, elas representam $45,28 \%$ e os homens $54,72 \%$.

Outro ponto a ser analisado é o aumento da média de idade dos professores ativos na educação básica no Brasil, como mostra a tabela a seguir, divulgada pelo MEC (Ministério da Educação e Cultura) em 2018:

Tabela 1 Estatísticas descritivas para a idade do professor-Brasil- 2009/2013/2019

\begin{tabular}{|c|c|c|c|c|c|c|c|c|}
\hline \multirow{2}{*}{\multicolumn{2}{|c|}{ ETAPA }} & \multicolumn{7}{|c|}{ IDADE DO PROFESSOR } \\
\hline & & \multirow{2}{*}{$\begin{array}{l}\text { Média } \\
38,65\end{array}$} & \multirow{2}{*}{$\begin{array}{r}\text { Desvio- } \\
\text { padráo } \\
9,79\end{array}$} & \multirow{2}{*}{$\begin{array}{r}\text { Mínima } \\
11\end{array}$} & \multirow{2}{*}{$\begin{array}{r}\text { Máxima } \\
89\end{array}$} & \multirow{2}{*}{$\begin{array}{r}\text { Mediana } \\
38\end{array}$} & \multirow{2}{*}{$\begin{array}{r}\text { Mada } \\
32\end{array}$} & \multirow{2}{*}{$\frac{N}{1.857 .278}$} \\
\hline \multirow{3}{*}{ BRASIL } & 2009 & & & & & & & \\
\hline & 2013 & 39,50 & 9,96 & 14 & 95 & 39 & 34 & 2.017 .071 \\
\hline & 2017 & 41,04 & 9.89 & 14 & 93 & 40 & 38 & 2.078 .910 \\
\hline \multirow{3}{*}{$\begin{array}{l}\text { EDUCAÇÃO } \\
\text { INFANTIL }\end{array}$} & 2009 & 36,24 & 9,19 & 11 & 81 & 35 & 30 & 377.560 \\
\hline & 2013 & 37.65 & 9,48 & 14 & 95 & 37 & 34 & 478.811 \\
\hline & 2017 & 39,47 & 9,55 & 14 & 93 & 39 & 36 & 557.541 \\
\hline \multirow{3}{*}{$\begin{array}{l}\text { ANOS } \\
\text { INICIAIS }\end{array}$} & 2009 & 36,25 & 9,45 & 12 & 83 & 38 & 32 & 737.833 \\
\hline & 2013 & 39,80 & 9,51 & 14 & 95 & 39 & 35 & 750.366 \\
\hline & 2017 & 41,40 & 9.54 & 14 & 86 & 41 & 38 & 761.737 \\
\hline \multirow{3}{*}{$\begin{array}{l}\text { ANOS } \\
\text { FINAIS }\end{array}$} & 2009 & 38,90 & 9,85 & 12 & 89 & 38 & 31 & 785.209 \\
\hline & 2013 & 39,67 & 10,08 & 14 & 95 & 39 & 32 & 802.902 \\
\hline & 2017 & 41,19 & 9,99 & 15 & 85 & 40 & 36 & 764.731 \\
\hline \multirow{3}{*}{$\begin{array}{l}\text { ENSINO } \\
\text { MEDIO }\end{array}$} & 2009 & 39,82 & 9,85 & 16 & 89 & 39 & 44 & 460.023 \\
\hline & 2013 & 40,40 & 10,27 & 14 & 95 & 40 & 33 & 507.617 \\
\hline & 2017 & 41,81 & 10,07 & 14 & 89 & 41 & 36 & 509.794 \\
\hline
\end{tabular}

Fonte: http://portal.inep.gov.br (p 29).

Os dados levantados na tabela 1 revelam um aumento da média de idade dos professores no país de 38,65 em 2009 para 41,04 em 2017, e podem ser interpretados de duas maneiras. Essa elevação pode representar maior experiência em sala de aula, pois, quanto maior é a idade, maiores serão as vivências profissionais. Por outro lado, a falta de renovação pode significar a perpetuação de um sistema educacional notadamente falho, que peca principalmente pela falta de proximidade do currículo escolar com a realidade de seus alunos.

Na tabela a seguir, o estudo mostra o percentual de professores por faixa etária:

Tabela 2 Percentual de professores por faixa etária-Brasil-2009/2013/2017

\begin{tabular}{|l|r|r|r|r|r|r|}
\hline & \multicolumn{2}{c|}{2009} & \multicolumn{2}{c|}{2013} & \multicolumn{2}{c|}{2017} \\
\hline & $\%$ & (acumul.) & $\%$ & (acumul.) & $\%$ & (acumul.) \\
\hline Até 20 & 0,8 & 0,8 & 0,7 & 0,7 & 0,4 & 0,4 \\
\hline De 21 a 30 & 23,0 & 23,8 & 19,5 & 20,2 & 15,1 & 15,5 \\
\hline De 31 a 45 & 50,9 & 74,7 & 51,1 & 71,3 & 51,6 & 67,1 \\
\hline De 46 a 56 & 21,0 & 95,7 & 23,5 & 94,8 & 26,3 & 93,4 \\
\hline De 57 a 65 & 4,0 & 99,7 & 4,7 & 99,5 & 5,9 & 99,3 \\
\hline Acima de 66 & 0,3 & 99,9 & 0,5 & 100,0 & 0,7 & 100,0 \\
\hline
\end{tabular}

Fonte: http://portal.inep.gov.br (p 31) 
A tabela 2 mostra que o número de professores com até 30 anos, que era de 24, 4 \% em 2009, caiu para 15,9 em 2017. Com os novos desafios da educação cada vez mais digital, esta queda prejudica a implementação de novos métodos de ensino, visto que os mais jovens notadamente possuem maior familiaridade com os recursos tecnológicos. Em contrapartida, os mais experientes preferem os métodos mais tradicionalistas de transmissão de conhecimento, distanciando-se ainda mais da realidade e das necessidades dos seus educandos.

\section{A CARREIRA DOCENTE ATRAI?}

Ao questionar um jovem que está cursando o Ensino Médio sobre a possibilidade de ele entrar na universidade para tornar-se professor, na maioria dos casos a resposta será negativa. Um estudo realizado em 2018 pela Fundação Victor Civita, encomendada pela revista Nova Escola mostrou que "a profissão docente não é considerada uma opção atraente pelos estudantes do Ensino Médio. Segundo a sondagem, só 2\% desejam cursar Pedagogia ou Licenciaturas” (RATIER e SALLA, 2013, p. 4).

No mesmo estudo, $32 \%$ dos entrevistados revelam que já tiveram o anseio de se tornar professor, mas que foram perdendo esta vontade devido ao fato de terem presenciado todos os desrespeitos sofridos pelo professor em sua rotina de trabalho e fora dela.

Dentre os motivos desta mudança de ambição estão o desinteresse e a falta de apreço por parte dos colegas, as pressões e o estresse causados pela constante cobrança de melhoria no desempenho (como se o culpado fosse somente o professor, e não toda a engrenagem educacional), a falta de remuneração digna e de um plano de carreira que garanta ao profissional o reconhecimento pelos serviços prestados. Tudo isso fez os poucos jovens que sonhavam com a docência abdicarem de sua vontade e seguir a tendência das profissões que oferecem maior prestígio social e bons salários.

Em razão do déficit de qualidade do ensino, ocasionado pela baixa procura dos cursos de licenciatura, o Governo Federal flexibilizou o ingresso e a formação de profissionais não licenciados que queiram ingressar na carreira de professor, na tentativa de atrair os bons profissionais de outras áreas para a sala de aula.

“Assim, para atender às novas demandas sociais, os cursos de Formação de professores vêm fazendo constantes ajustes em seus projetos pedagógicos. A última alteração se deu em função das Resoluções CNE. nº 02 de 2015/2019 que estabeleceu novas regras e diretrizes para a formação de professores no Brasil”, afirmam PURIFICAÇÃO et al. (2020, p, 201). Segunda a referida Resolução no capítulo VI, artigo 21, “o graduado não licenciado que queira entrar no magistério terá que realizar uma carga horária de estudo de 760 horas. " A carga horária exigida anteriormente era de 1400 horas, número bem maior que o atual. Para se ter uma noção mais clara, esse tempo é menor que as 800 horas práticas na formação inicial do professor.

Não se pode investir apenas na oferta quantitativa de cursos de formação para suprir o déficit de professores, sem a preocupação com a qualidade desta formação. Essa diminuição no tempo de curso para não licenciados demonstra a banalização da formação docente, pois a recíproca não é verdadeira. Se um professor quiser ser engenheiro, indubitavelmente não terá a facilidade encontrada no processo contrário. Mais difícil ainda será encontrar bons profissionais formados em outras áreas que queiram migrar para a instável carreira de professor. A explanação mais plausível seria por pura filantropia ou altruísmo diante dos parcos mecanismos de sedução da profissão docente.

\section{SER PROFESSOR: UMA QUESTÃO DE IDENTIFICAÇÃO}

O professor é responsável pela garantia de que os conhecimentos acumulados pelas gerações anteriores sejam passados para as próximas gerações, além de aperfeiçoá-los para se ajustarem à constante mudança de demandas em busca de uma sociedade melhor.

Sobre o perfil do professor, Libâneo aponta que as

$$
\begin{aligned}
& \text { novas exigências educacionais pedem às universidades e cursos de formação para o magistério um professor } \\
& \text { capaz de ajustar sua didática às novas realidades da sociedade, do conhecimento, do aluno, dos diversos } \\
& \text { universos culturais, dos meios decomunicação. O novo professor precisaria, no mínimo, de uma cultura } \\
& \text { geral mais ampliada, capacidade de aprender a aprender, competência para saber agir na sala deaula, } \\
& \text { habilidades comunicativas, domínio da linguagem informacional, saber usar meios de comunicação e } \\
& \text { articular as aulas com as mídias e multimídias. (LIBÂNEO, 1998, p.10). }
\end{aligned}
$$

O professor da rede pública, em sua origem, estuda numa escola sem as devidas condições de aprendizagem para concorrer nos processos seletivos de carreiras mais promissoras, como medicina, engenharia, direito. Sem poder concorrer a essas 
vagas em universidades públicas, nem pagar os altos preços das privadas, a carreira docente desponta como possibilidade de ingressar em um curso superior com grande oferta de mercado e baixo custo.

Esse ingresso por conveniência ou falta de opção torna impossível a identificação do profissional com seu ofício, visto que, quem trabalha apenas pelo sustento, e não por amor, não se preocupa com sua formação continuada, e menos ainda com o resultado de seu trabalho.

Quando não trabalha com entusiasmo, o professor deixa de ser um espelho para seus alunos, gerando distanciamento na relação aluno/professor. Este afastamento transcende o espaço físico da sala de aula. De um lado, fica o professor frustrado com sua profissão e sem perspectiva de mudança de paradigma, do outro o aluno que não se sente motivado a aprender, enxergando a escola como obrigação institucional imposta pelos pais e leis educacionais.

Garcia, Hypólito e Vieira definem a identidade profissional do professor como

(...) uma construção social marcada por múltiplos fatores que interagem entre si, resultando numa série de representações que os docentes fazem de si mesmos e de suas funções, estabelecendo, consciente ou inconscientemente, negociações das quaiscertamente fazem parte de suas histórias de vida, suas condições concretas de trabalho,o imaginário recorrente acerca dessa profissão (...) (2005, p. 54-55).

As representações de si mesmo citadas pelos autores são marcadas por frustrações desde o começo de sua vida escolar, quando o futuro professor vê seus mestres sem motivação, sendo desrespeitados de todas as formas e por todos os setores da sociedade, inclusive os próprios alunos que ele almeja instruir.

Ao presenciar esse contexto em sua formação, o aluno constrói seu próprio imaginário sobre "ser professor" (esse "ser" pode ser entendido como ato de ser professor, ou o ser humano professor). Esse contato descaracteriza a imagem que o discente traz consigo do professor detentor de todos os saberes, dono da ternura e sapiência que só os grandes mestres têm. Essa quebra de imagem revela um profissional amargurado com o trabalho, e um ser humano frustrado, vítima de uma corrente de desvalorização espalhada por toda a sociedade.

Por consequência, esse aluno tende a se distanciar do desejo inicial de tornar-se professor, voltando a reconsiderar essa possibilidade mais adiante não por opção, mas por falta dela.

\section{CONSIDERAÇÕES FINAIS}

A necessidade de mudança é evidente, e desde a promulgação da Constituição Federal de 1988 criou-se um consenso da urgência de valorização da educação e seus profissionais, entretanto isto não ocorre. O que pode estar errado em um país que consegue colocar $98 \%$ de seus jovens de 7 a 14 anos na escola.? Por que se investe tanto em educação, sem conseguir colher os frutos?

Para mudar a história, o governo tem investido em políticas de apoio ao financiamento estudantil, melhoria do currículo, sistema de avaliação (que é um dos mais amplos do mundo), mudanças estruturais no ensino fundamental e médio. Mas nada disso adianta se não voltar os olhos para a valorização do professor, pois, se não há atratividade, não haverá interesse dos alunos com bom desempenho para cursar a docência. Eles continuarão escolhendo carreiras que são mais valorizadas. É necessário cativá-los a se enxergarem como professor, tornando o ambiente escolar um local de acolhimento e respeito às diferenças, não de segregação e exclusão. Para isso, necessita-se de políticas de melhoramento da atratividade da profissão, condições de trabalho adequadas e plano de carreira, para que o professor também possa se sentir acolhido.

A formação inicial não prepara adequadamente, por isso, é preciso implementar formas de melhoria da formação inicial e continuada dos docentes, aliando os conteúdos teóricos a uma forte interação com a prática, dando condições para ele investir em sua carreira. Para isso, é preciso melhorar as condições salariais para diminuir a carga horária de trabalho aos quais são 
submetidos. É preciso uma política de valorização que o faça trabalhar com menos turmas, se possível na mesma escola. Além disso, o professor necessita de horas de trabalho pedagógico fora do ambiente escolar, como tempo para preparar aulas e corrigilas, participação em cursos de capacitação e visita aos alunos para entender melhor suas reais necessidades.

Na maioria dos sistemas educacionais do Brasil, os professores com maior experiência dão preferência às escolas mais centralizadas, onde estão os alunos de melhor condição social e capital cultural. Como resultado, as escolas de bairros carentes recebem professores recém-formados ou até graduandos de licenciatura, que não possuem bagagem curricular para oferecer um ensino de qualidade. Ao perceber essa diferença, o aluno de áreas mais carentes se decepciona com a escola que ele um dia acreditou ser um dos únicos locais onde estaria protegido da segregação e de todos os preconceitos que ele sofre.

Este trabalho não tem a pretensão de desmerecer o trabalho do professor, qualificando- o como bom ou ruim; menos ainda almeja-se tirar-lhe o direito de escolha do local de trabalho que conquistou por direito. A intensão é trazer à tona a necessidade de políticas de incentivo à alocação desses profissionais com maior experiência nas escolas onde há mais dificuldade de aprendizagem, oferecendo gratificações e melhores condições de trabalho, além de garantir formação de qualidade a todos os professores, e não apenas quantidade. Somente assim poderá ser oferecida uma educação transformadora nos lugares que mais necessitam dela.

\section{REFERÊNCIAS}

BOURDEIRU, Pierre. O Poder Simbólico. Rio de Janeiro. Bertrand Brasil. 2000.

DE CARVALHO, Maria Regina Viveiros. Perfil do professor da Educação básica; Disponível em: http://portal.inep.gov.br/informacao-da-publicacao

FREIRE, Paulo. A Éducação na Cidade. São Paulo: Cortez, 1991.

GARCIA, Maria M. A.; HYPOLITO, Alvaro M.; VIEIRA, Jarbas S. As identidades docentes como fabricaçãoda docência. Educação e Pesquisa. São Paulo, v.31 n.1, pp.45-56, jan./mar. 2005.

GENTILI, Pablo. Desencanto e Utopia: A educação no labirinto dos novos tempos. Petrópolis: Vozes,2008.) 3

HYPOLITO, A. M.; VIEIRA, J. S. Reestruturação educativa e trabalho docente: autonomia, contestação e controle. In: Hypolito, A. M.; Vieira, J. S.; Garcia, M. M. A. Trabalho docente:formação e identidades. Pelotas: Seiva Publicações, 2002. p.271-283.

LIBÂNEO, José Carlos; Adeus professor, adeus professora? Novas exigências educacionaise profissão docente. São Paulo: Atlas. p.04.

LIBANEO, José Carlos. Adeus professor, Adeus professora? Novas exigências educacionais e profissão docente. São Paulo, Cortez, 1998.

PALHARES, Isabela; Relatório Políticas Eficientes para Professores; Realizado pelaOrganização para a Cooperação e Desenvolvimento Econômico (OCDE); disponível em:https://educacao.estadao.com.br/noticias/geral,so-2-4-dos-jovensbrasileiros-querem-ser- professor,70002364548; Acesso: em 08/jun/2020.

PURIFICAÇÃO, Marcelo Máximo; Catarino, Elisângela Maura; Teixeira, Maria Filomena Rodrigues; Santana, Lousana de Jesus; Abdalla, Cláudia de Souza; Alves, Angélica Ferreira (2020). Curriculum and Identity its Impacts on the School Context in Goiás: Points and Counterpoints. Am. In. Mult. J., Jul to Oct. (9) 5, 196-204

RATIER, Rodrigo; SALLA, Fernanda; Por que a docência não atrai; Pesquisa realizada pelaFundação Victor Civita (FVC) e da Fundação Carlos Chagas (FCC); Disponível em: https://novaescola.org.br/conteudo/7157/por-que-a-docencia-nao-atrai

RESOLUÇÃO CNE/CP $\mathrm{N}^{\circ} \quad 2$, DE 20 DE DEZEMBRO DE 2019, Disponível em: http://portal.mec.gov.br/docman/dezembro-2019-pdf/135951-rcp002-19/file; Acesso em: 06/jun/2020

SFORNI, Marta Sueli de Faria. Escola Pública e Feminização Docente: faces do mesmo projeto. In Anais do IV Seminário Nacional HISTEDBR - Grupo de Estudos e Pesquisas História, Sociedade e Educação no Brasil”, Faculdade de EducaçãoUNICAMP, Campinas, de14 a 19 de dezembro de 1997, CD-Rom. 
Informações sobre os autores:

SFA: Graduado em Letras -Português/Inglês pelo Centro Universitário de Jales - UNIJALES. Assistente em administração na Universidade Federal do Triângulo Mineiro UFTM. Mestrando em Educação na Universidade Estadual do Mato Grosso do Sul - UEMS - E-mail: sidnei.araujo1980@gmail.com

MMP: Pós-Doutor em Educação pela Universidade de Coimbra - Portugal. Doutor em Ciências da Religião pela PUC-Goiás (2014). E Doutor em Ensino pela UNIVATES (2021). Graduado em Matemática, Pedagogia e Filosofia. Professor permanente do mestrado em educação da Universidade Estadual do Mato Grosso do Sul - UEMS. E-mail: maximo@unifimes.edu.br

Contribuições dos autores: (SFA; MMP) conceitualização, captação de recursos, supervisão, redação.

Fonte de financiamento: Nenhum

Conflito de interesse: Os autores declaram não haver nenhum conflito de interesse.

E-mail do autor-correspondência: sidnei.araujo1980@gmail.com

Data de recebido: 08/09/2020

Data de aprovado: $12 / 12 / 2020$

Editora: Elisângela Maura Catarino.

Este é um artigo publicado em acesso aberto (Open Access) sob a licença Creative Commons Attribution, que permite uso, distribuição e Reprodução em qualquer meio, sem restrições desde que o trabalho original seja corretamente citado. 